\title{
VIOLÊNCIA, ESCOLA E JOVENS DE GRUPOS POPULARES URBANOS: O CASO DE ESTUDANTES DE ENSINO MÉDIO SÃO CARLOS/SP ${ }^{1}$
}

\author{
Roseli Esquerdo Lopes ${ }^{2}$ \\ relopes@ufscar.br \\ Carla Regina Silva ${ }^{3}$ \\ carla.metuia@gmail.com \\ Beatriz Rocha Moura ${ }^{4}$ \\ beatriz-to@hotmail.com \\ Jorge Oishi $^{5}$ \\ djoi@ufscar.br
}

Universidade Federal de São Carlos - UFSCar

\section{RESUMO:}

Tomando-se o caso de adolescentes e jovens que freqüentam a escola pública de Ensino Médio em São Carlos/SP, tratou-se de conhecer e analisar suas condições sócioeconômicas, seus problemas e perspectivas de estudo e de vida escolar e, também, de discutir a avaliação que fazem acerca do fenômeno da violência na e da escola. Configurada uma amostragem representativa para o ano de 2006, contatou-se as direções escolares, fazendo-se os acertos necessários para a realização da pesquisa. Trabalhou-se com um instrumento com questões abertas e fechadas. A escola é uma referência fundamental para a grande maioria dos alunos. Apesar de mais da metade dos jovens não considerarem sua escola violenta, o mesmo percentual refere a ocorrência de situações e de atitudes de violência na escola. Nossa pretensão é que esse perfil possa oferecer subsídios para estratégias de enfrentamento da violência na escola, associadas à promoção dos direitos e ao contato relacional com respeito e dignidade.

Palavras-chave: Adolescência e Juventude; Cidadania e Direitos; Escola Pública; Ensino Médio; Violência Escolar.

\section{VIOLENCE, SCHOOL AND YOUTH: \\ THE CASE OF PUBLIC HIGH SCHOOL STUDENTS IN SÃO CARLOS/SP}

\begin{abstract}
:
From the case sample of teenagers and young people who attend public high school in São Carlos/SP, this article analyzes their social-economical conditions, their problems and what they expect from their school life as well as discusses their evaluation about the violence in and from the school. Choosing students from several public schools as a sample, we contact the school directors and arranged everything that was necessary for
\end{abstract}


the realization of the research. A questionnaire was used with opened and closed questions. The school is a fundamental reference for the majority of the students. Although half of the students do not consider their school violent, the same number of students tells us about violent situations and violent actions in school. We aim that this research can help to build strategies to combat the violence in school, together with promoting the rights and relationships with respect and dignity.

Key Words: Adolescence and Youth; Citizenship and Rights; Public School; High School; School Violence.

\section{Introdução}

\section{Juventude, Direitos e Violência}

Vivemos num mundo jovem. Há 1,2 bilhões de jovens no mundo, cerca de $50 \%$ da população mundial possui até 25 anos e a próxima geração poderá atingir números ainda maiores, aproximadamente 1,8 bilhões. Torna-se evidente a necessidade de investimento social nessa população, quando se lida com dados que demonstram que cerca de 209 milhões de jovens são pobres ${ }^{6}$, 130 milhões são analfabetos, 88 milhões são desempregados e 10 milhões vivem com o HIV/Aids (ONU, 2005).

Para a Organização Mundial de Saúde, a adolescência constituiria um processo fundamentalmente biológico, durante o qual se aceleraria o desenvolvimento cognitivo e a estruturação da personalidade, abrangendo as idades de 10 a $19 \operatorname{anos}^{7}$. Já o conceito de juventude resumiria uma categoria sociológica, que indicaria o processo de preparação para os indivíduos assumirem o papel de adulto na sociedade, tanto no plano familiar quanto no profissional, estendendo-se dos 15 aos 24 anos (OMS/OPS, 1985).

O debate acerca das concepções com relação à juventude e à adolescência é essencial, pois a partir delas serão retratadas e interpretadas suas formas de ser e estar no mundo e, além disso, a maneira como a sociedade se organiza na atenção a essas fases da vida, especialmente o modo como são configurados os direitos e os deveres dos adolescentes e dos jovens e quais são as ações sociais e políticas reivindicadas (Lopes et al., 2008, p.65).

Nessa perspectiva, a população jovem pobre é a mais vulnerável e apresenta maior desvantagem; possui menos experiência profissional, pouca qualificação, maior propensão a acidentes e, conseqüentemente, menor acesso ao mundo do trabalho o que 
acarreta a redução das suas oportunidades e/ou a sua absorção, apenas, na economia informal. Essa situação mantém a irregularidade do trabalho para o jovem pobre, realimentando um ciclo contínuo de inserção precária ou de exclusão, trazido da condição social. No campo educacional, sabe-se que as crianças que vivem em países pobres correm maior risco de não freqüentarem a escola, além de terem mais dificuldades de nela se manterem, bem como de estarem submetidas a piores níveis de qualidade na educação (ONU, 2005).

Dados apresentados pelo IBGE, em 2005, apontam que 23\% da população entre 16 e 24 anos não estudava e não trabalhava; a Pesquisa Nacional por Amostragem de Domicílios (PNAD/IBGE) indica que 20\% dos jovens de 15 a 24 anos não estavam ocupados nem estudando em 2004 (FSP, 2006).

Nesse contexto, prevalece o estigma dos jovens pobres como "desocupados", "perigosos", "violentos" e que devem ser controlados, o que se percebe refletido, indiretamente, no precário estabelecimento de ações direcionadas a essa população, cristalizando uma cultura que se afasta, concreta e simbolicamente, da discussão da garantia de direitos.

A vulnerabilidade desses adolescentes e jovens, expressa, também, por inúmeros índices relacionados à violência ${ }^{8}$, tem alcançado patamares alarmantes no nosso país, num contexto de políticas públicas que são, em grande parte, insuficientes, fragmentadas e/ou inadequadas (Lopes et al., 2006).

Diante de tamanha desigualdade social e das demandas correlatas geradas, é extremamente necessário o trabalho especializado na construção de uma rede de proteção à juventude. Entretanto, observa-se uma escassez de experiências, de produção de material sobre meios de intervenção e, sobretudo, do uso de formas múltiplas para o estabelecimento do diálogo que se dediquem à produção de tecnologias sociais, à criação de espaços de participação democrática e que ampliem a rede de possibilidades desses jovens, na direção de, concretamente, envolvê-los numa atenção que tenha como parâmetro a possibilidade de construção de perspectivas de futuro, a partir da autonomia do sujeito envolvido.

Nesse caminho, a escola pública aparece como o equipamento social fundamental. 


\section{Violência e Escola}

A constituição das instituições escolares, desde o seu início, se correlaciona a processos de violência, embora estes termos tenham se transformados ao longo do tempo. A família e a escola retiraram, juntas, a criança da sociedade dos adultos. A escola confinou uma infância outrora livre num regime disciplinar que, nos séculos XVIII e XIX, levou ao enclausuramento total no internato. A solicitude da família, da igreja, dos moralistas e dos administradores, privou a criança da liberdade de que gozava entre os adultos. Infligiram-se o chicote, a prisão, em suma, correções reservadas aos condenados (Ariès, 1981).

Pontua-se que as crianças escolarizadas vinham das elites e que a sociedade contemporânea não admite mais os antigos métodos disciplinares como educativos.

Assim, ressalta-se a importância de se contextualizar o fenômeno da violência na escola em relação às condições políticas, econômicas, culturais e sociais as quais estão inter-relacionadas, especialmente, na formação da universalidade e da individualidade nas esferas dos direitos humanos e da cidadania. As relações de sociabilidade passam por mudanças, mediante processos simultâneos de integração comunitária e de fragmentação social, de massificação e de individualização, de seleção e de exclusão social. Nesse contexto, novos dilemas e problemas sociais emergem no horizonte mundial, configurando novas questões (Castel, 1998).

Os estudos acerca das práticas de violência nas escolas ganharam maior destaque no âmbito do debate público nacional no início dos anos 1980. Isto porque, por um lado, segundo Sposito (2001), demandas latentes adquiriram visibilidade nos espaços criados pela distensão política, propiciando maior abertura para as questões que afetavam a qualidade de vida da população das periferias das grandes cidades, onde a segurança constituía um problema importante. De outro, tratava-se, naquele momento, de lutar por uma maior democratização das instituições oficiais - sobretudo dos aparelhos de segurança - resistentes aos novos rumos trilhados pelo país.

As práticas de violência podem ser compreendidas no interior das escolas e na interpretação dos atores envolvidos como uma resposta às precárias condições de sobrevivência com as quais comunidades excluídas se defrontam. Sabemos que essas práticas dentro da escola não acontecem isoladamente e que, pelo contrário, 
demonstram o quanto a escola é vulnerável e reflexo da sociedade na qual se insere. Em uma outra linha, aponta-se a falta de limites, de regras, enfocando o indivíduo, podendo até considerá-lo delinqüente, problemático, entre outros estigmas. Muitas vezes, o risco de classificar como patológicos os comportamentos "desordeiros" encontra-se presente, inocentando as instituições sociais da geração de violência (Debarbieux e Blaya, 2002).

O problema da exclusão nos revela algumas das contradições enfrentadas pela escola, como instrumento para maiores chances de acesso a bens sociais e melhores condições de vida, e como agente de uma exclusão específica que transforma a experiência dos alunos e abre uma crise de sentido nos estudos, às vezes até da legitimidade da instituição escolar.

A escola, hoje, convida a nos interrogarmos sobre as finalidades da educação. Aquela ambigüidade presente na escola, tida como meio extremamente necessário e importante, exclui aquele que não ingressa nesse modelo ou que não consegue nele se manter. Com efeito, a exclusão escolar é o resultado "normal" da extensão de uma escola democrática de massa que afirma ao mesmo tempo a igualdade dos indivíduos e a desigualdade de seus desempenhos. Nesse sentido, a escola integra mais e exclui mais que antes (Dubet, 2003).

A violência seria a relação social de excesso de poder que impede o reconhecimento do outro - pessoa, classe, gênero, etnia - mediante o uso da força ou da coerção, provocando algum tipo de dano, configurando o oposto das possibilidades da sociedade democrática contemporânea (Tavares dos Santos, 2001).

Para Sposito (2001), a intensidade e a complexidade desse fenômeno demandam um intenso trabalho de pesquisa e somente nos últimos anos tem mobilizado, de forma mais nítida, os investigadores de algumas instituições de ensino superior e organizações não governamentais. Aliado a isso, a sociedade brasileira se depara cada vez mais com o aumento significativo da violência na escola, fato este que, segundo Abramovay \& Rua (2002), despertou a atenção das diversas instâncias governamentais, dos organismos internacionais e da sociedade civil.

É importante ressaltar que a maioria das pesquisas realizadas sobre esse tema trouxe estudos empíricos de grandes centros urbanos, onde tal questão apresenta maior incidência e visibilidade, especialmente a partir de outros setores como a mídia. Existe, 
contudo, pouca discussão quando se trata de cidades de pequeno e médio porte, nas quais essa problemática não tem, ainda, maiores dimensões e, portanto, são passíveis de intervenções com melhores probabilidades de êxito, desde que compreendidas suas razões.

Acreditamos que estudos como o que aqui apresentamos, considerando o caso da cidade de São Carlos (SP) como típico para uma gama importante de municípios brasileiros, podem contribuir para a elaboração de políticas públicas envolvendo educação, juventude e o fenômeno da violência na e da escola, sem dúvida, um desafio para a educação do século XXI.

\section{Procedimentos da Pesquisa}

Nossa intenção foi conhecer, analisar e discutir o perfil sócio-econômico dos adolescentes e jovens que freqüentam a escola pública de Ensino Médio em São Carlos $(\mathrm{SP})^{9}$ e reconhecer sua avaliação acerca do fenômeno da violência na escola, trabalhando-se a partir de uma visão que busca abordar o objeto de pesquisa de modo a apreender sua realidade concreta, lançando mão de dados quantitativos que, aliados aos dados qualitativos de outros projetos com os quais trabalhamos, possam melhor dimensionar os problemas e questões sobre os quais se debruça.

Assim, em uma primeira etapa, foi levantado o número de estudantes matriculados na rede pública de Ensino Médio em São Carlos, no ano de 2006. Em seguida, trabalhou-se na definição de uma amostragem que fosse representativa desse grupo populacional no sistema de ensino público do Município. Foram contatadas as direções das escolas onde foi realizada a pesquisa e feitos os acertos técnicos e éticos necessários para a consolidação do desenho do estudo de campo. Paralelamente, foi elaborado e testado um questionário com perguntas fechadas e abertas para a coleta dos dados, composto por três partes: perfil sócio-econômico, vida escolar, violência escolar, e, ainda, por um espaço livre para outras observações dos alunos. Foram aplicados 1.445 questionários em cinco escolas públicas de Ensino Médio. Posteriormente, realizou-se o tratamento dos dados coletados, com a codificação das questões e análise estatística, oferecendo parâmetros para sua discussão. 


\section{Resultados e Discussão}

Segundo dados do Censo Escolar 2006 (Brasil, 2006), São Carlos apresentou 9.480 alunos matriculados no Ensino Médio, sendo que destes, 1.950 alunos estavam na rede privada e 7.530 alunos estavam matriculados em escolas públicas estaduais ${ }^{10}$. Os questionários aplicados alcançaram 15\% dos alunos matriculados, seja de escolas públicas ou privadas, e 19,2\% dos alunos matriculados em escolas públicas.

Em relação ao total de questionários válidos, temos a soma de 48 turmas do Ensino Médio, na qual as turmas de primeiro ano representam $42 \%$ do total, as turmas de segundo ano $33 \%$ e, portanto, as turmas de terceiro ano significam $25 \%$. A proporcionalidade com relação ao período em que os alunos estudam foi condizente com a representação de todo sistema de Ensino Médio das escolas públicas da cidade.

\section{PERFIL SóCIO-ECONÔMICo}

\section{A - Dados Pessoais}

Com uma idade média de 16 anos, $45 \%$ dos jovens são rapazes e 55\% são garotas. $62 \%$ declaram-se brancos, $14 \%$ negros, $4 \%$ amarelos, $19 \%$ de outra cor, sendo essa categoria composta por uma maioria de $\operatorname{pardos}^{11} \cdot 92,1 \%$ dos jovens são solteiros, $5 \%$ casados, $0,5 \%$ separados, $0,6 \%$ viúvos, $2,7 \%$ optaram pela categoria 'outros', estando a maioria destes morando com companheiro ou companheira. $4 \%$ indicaram serem pais (possuem pelo menos um filho).

Com relação aos bairros e localidades em que residem, estes se apresentam numa ordem decrescente que vai daqueles que estão na periferia da cidade para aqueles das regiões mais centrais e centrais.

A maioria de suas famílias compõe-se por pai, mãe e irmãos; alguns moram com padrasto, avós ou tios. Quando se utilizou a categoria 'outros', majoritariamente, a referência foi sogros e cunhados. Quanto ao número de cômodos, suas residências têm 5,5 cômodos, onde vivem, em média, 5 pessoas. 
A maior parte das famílias (60\%) tem uma renda familiar mensal entre 1 e 4 salários mínimos. $4 \%$ das famílias recebem menos de 1 salário mínimo. A minoria das famílias vive com mais de 6 salários mínimos. Em relação às pessoas que contribuem para a renda familiar, os maiores contribuintes são: pai (69\%), mãe (59\%), irmãos (20\%) e o próprio jovem (20\%).

Quando comparadas as diferenças de renda familiar entre escolas situadas em regiões centrais e escolas situadas em regiões periféricas da cidade ${ }^{12}$, observa-se uma grande discrepância. Nas escolas periféricas, as rendas familiares concentram-se na faixa de 1 a 4 salários mínimos (64\%); observa-se, também, que pouquíssimos alunos marcaram as opções acima de 6 salários mínimos (6\%). Já nas escolas centrais, 18\% das famílias possuem renda entre 3 e 4 salários mínimos, porém as outras opções também obtiveram porcentagens significativas; ou seja, verifica-se que nas escolas centrais existem alunos com todas as faixas de renda familiar. Isto ocorre pelo fato das escolas centrais receberem alunos de diversos bairros da cidade, enquanto as escolas periféricas recebem, principalmente, alunos de bairros mais próximos.

\section{B - Família e Responsáveis}

A maioria dos jovens tem como responsáveis o pai e a mãe. Na categoria 'outros' se encontram: marido, sogros, cunhados e o próprio jovem. Apenas 55\% desses responsáveis possuem emprego fixo. Com relação às funções que os responsáveis exercem e/ou setor em que trabalham, a maior parte é prestadora de serviços, 12,2\% são trabalhadores domésticos, $10 \%$ são trabalhadores da indústria, 6,2\% trabalham na construção civil, 5,5\% são trabalhadores do comércio, 3,3\% são donas de casa. A minoria trabalha no setor público, é profissional liberal ou trabalhador rural.

Os dados demonstram, no que se refere ao grau de escolaridade dos responsáveis, que a maioria possui o Ensino Fundamental incompleto, 19,2\% possuem o Ensino Superior completo e 1,2\% possuem o Ensino Médio completo. Apesar da alta porcentagem de Ensino Superior completo (19,2\%), muitas funções no trabalho não corresponderam a esse grau de escolaridade. 


\section{C - Trabalho}

A maioria dos jovens não trabalha, $42 \%$ por se dedicarem aos estudos, $35 \%$ por estarem procurando emprego e $10 \%$ já trabalharam, mas, naquele momento, não o faziam. Dos jovens que trabalham, 14\% referem ser uma escolha e 12\% uma necessidade. Com relação aos jovens que trabalham ou que já trabalharam, a maioria atua/atuou no comércio ou presta/prestou algum serviço.

Ainda com relação ao tema, foram comparados os dados referentes a alunos do $1^{\circ}$ e do $3^{\circ}$ anos do Ensino Médio. Do $1^{\circ}$ para o $3^{\circ}$ ano, praticamente, dobra a porcentagem de jovens que trabalham porque precisam; verifica-se, portanto, uma inclusão progressiva de jovens no trabalho durante o Ensino Médio.

As diferenças mostram-se ainda maiores quando comparados alunos do período noturno e do período diurno ${ }^{13}$. Há um aumento da porcentagem em mais de 6 vezes para alunos que trabalham porque precisam, sendo que $44 \%$ dos alunos do período noturno encontram-se nessa situação, enquanto que do período diurno somente 7\%. Na categoria 'não trabalho, me dedico aos estudos', a situação se inverte: $40 \%$ dos alunos do período diurno marcaram essa opção e no período noturno esse número cai para $25 \%$. Os dados mostram que a grande maioria dos estudantes do período noturno trabalha, preenchendo seu dia com duas atividades: escola e trabalho. Esse quadro pode favorecer problemáticas como o cansaço e o desânimo que, muitas vezes, levam ao abandono escolar, como indicam diversos autores (Gonçalves et al., 2005; Marcílio, 2005; Zibas, 2005).

\section{D - Tempo Livre}

Analisou-se o que os jovens fazem no seu tempo livre e em quais cursos e projetos estão inseridos. 


\begin{tabular}{rc}
\hline \multicolumn{1}{c}{ Tabela 1: Uso do Tempo Livre } \\
Atividade & Percentual \\
Ouvem música & $71 \%$ \\
Assistem à TV & $67 \%$ \\
Estudam & $52 \%$ \\
Passeiam/Saem & $48 \%$ \\
Realizam tarefas domésticas & $43 \%$ \\
Namoram & $39 \%$ \\
Praticam esporte & $39 \%$ \\
Ficam na rua com amigos & $33 \%$ \\
Navegam na rede (Internet) & $33 \%$ \\
Fazem cursos & $26 \%$ \\
Freqüentam algum clube & $19 \%$ \\
Vão ao cinema & $15 \%$ \\
Participam de atividade cultural & $10 \%$ \\
\hline Participam de algum projeto & $6 \%$ \\
\hline
\end{tabular}

Observa-se que a minoria dos jovens faz cursos, freqüenta algum clube, vai ao cinema, participa de atividades culturais e projetos. Esses dados podem significar a falta de acesso dos adolescentes e jovens a esses tipos de atividades ou a falta de oferta dessas atividades na cidade.

Com relação a outros cursos, $74 \%$ dos jovens deixaram a questão em branco. Dentre os que responderam, $7 \%$ estudam outros idiomas, $24 \%$ cursam computação e $28 \%$ não ofereceram especificações. $\mathrm{Na}$ comparação das participações dos jovens de escolas centrais e periféricas em projetos e cursos, a participação dos jovens em cursos é praticamente a mesma (30\%), entretanto, com relação a projetos, $12 \%$ dos jovens de escolas periféricas participam de algum, já em escolas centrais esta participação é de somente 4\%. O maior índice de participação de jovens de escolas periféricas em projetos pode ser explicado pela concentração destes em espaços na periferia da cidade ou, então, pela escolha da população alvo atendida por esses projetos que, muitas vezes, priorizam crianças e adolescentes em situação de vulnerabilidade social. 


\section{ESCOLA}

O prolongamento da escolaridade tornou-se necessário, sobretudo em relação ao mercado de trabalho que exige cada vez mais um melhor nível de escolaridade. Nesse contexto, a Lei de Diretrizes e Bases da Educação Nacional (1996) reformula o Ensino Médio com o objetivo de expandi-lo e de melhorar sua qualidade, tornando-o parte da Educação Básica e estabelecendo, como dever do Estado, a progressiva extensão de sua obrigatoriedade.

Porém, dados de 2001 da PNAD/IBGE indicam que, na faixa etária de 15 e 17 anos, apenas $37 \%$ dos jovens encontravam-se matriculados nesse nível de ensino. Vários motivos podem estar relacionados a essa realidade como a distorção série/idade, a evasão escolar, a necessidade de trabalhar, a baixa qualidade do ensino, entre outros.

Nesta pesquisa, objetivou-se, também, conhecer o que os alunos inseridos no Ensino Médio pensavam acerca da escola e como a avaliavam, assim como coletar dados referentes à sua vida escolar, às suas perspectivas e aos seus interesses. A seguir, serão apresentados esses dados que compuseram a segunda parte do questionário.

Os adolescentes e jovens freqüentavam a escola em que estavam matriculados no momento da pesquisa, numa média de mais de 3 anos. Quando questionados sobre a importância do Ensino Médio, 67\% dos jovens responderam que estar cumprindo esse nível de ensino os ajuda a ter um futuro melhor, 54\% consideram-no importante, pois prepara para o vestibular, $47 \%$ porque prepara para o mercado de trabalho e $30 \%$ porque os educa para serem cidadãos. Foram comparados dados sobre a importância do Ensino Médio para alunos de escolas centrais e periféricas. Dentre as diferenças mais significativas o vestibular teve um porcentual maior para alunos de escolas centrais, assim como o mercado de trabalho para os alunos de escolas periféricas.

Sobre a qualidade da escola, a maioria a considera boa, 20\% a consideram regular, $14 \%$ a consideram excelente e $4 \%$ a consideram péssima. Nesta questão, observa-se que a maior parte dos alunos de escolas centrais avalia sua escola como boa. Já para a maioria dos alunos de escolas periféricas a escola é considerada regular. Ainda, no questionário, os alunos puderam dar uma nota para suas escolas. Em uma 
escala de 0 a 10, a média de nota das escolas foi de 6,7. As escolas periféricas obtiveram a média de 6,8 e as escolas centrais de 7,6. Esses dados podem significar que, mesmo havendo dificuldades, as escolas centrais em São Carlos continuam sendo referências de escolas públicas "boas" e, por isso, melhor avaliadas e, conseqüentemente, mais procuradas por jovens de todos os bairros da cidade.

Quando questionados se já foram reprovados, 74\% dos alunos responderam que não, $25 \%$ que sim e $1 \%$ não respondeu.

$12 \%$ dos alunos deixaram de freqüentar a escola em algum momento da trajetória escolar, em um tempo médio de 1 ano e 2 meses. Em relação à série em que deixaram de freqüentar a escola, a maioria - $33 \%$ - deixou a escola na $1^{\mathrm{a}}$ série do Ensino Médio. Acerca dos principais motivos que os fizeram deixar de freqüentar a escola, indicou-se: problemas de saúde, a busca ou necessidade do trabalho, falta de interesse, vontade e motivação, mudança de cidade e falta de vaga.

16\% dos alunos referem já terem pensado em abandonar a escola. Os principais motivos que os fizeram pensar em abandonar a escola foram o cansaço e o desânimo, a falta de interesse, vontade e motivação, o trabalho e o fato de não gostarem da escola.

Com relação ao espaço físico, existe uma diferença de avaliação entre alunos de escolas centrais e de escolas periféricas. Nota-se, de forma significativa, que a maior parte de alunos de escolas centrais considera bom o espaço físico escolar, já para a maioria dos alunos de escolas periféricas o espaço físico escolar é regular. É importante salientar que uma das escolas centrais fica em um edifício que é patrimônio histórico da cidade de São Carlos, bastante valorizado pela população. Este fato pode explicar a alta porcentagem de 'bom' na avaliação das escolas centrais.

Quando questionados sobre como avaliam os professores, 59\% os consideram bons, $20 \%$ regulares, $19 \%$ excelentes e $1 \%$ ruins. Esta boa avaliação dos professores é maioria tanto em escolas centrais quanto nas periféricas.

Grande parte (43\%) dos alunos avaliou a direção da escola como boa, 30\% como regular, $18 \%$ como excelente e $9 \%$ como ruim.

No que respeita à qualidade do ensino, a maior parte dos estudantes opta pela categoria 'bom', $23 \%$ pela excelente e $2 \%$ pela ruim. Quando questionados sobre o 
quanto aprendiam na escola, $60 \%$ declaram que o suficiente, $23 \%$ muito, $13 \%$ pouco e $2 \%$ muito pouco.

Quanto à importância da participação dos alunos nas decisões da escola, assim como à existência de espaços democráticos de participação, 90\% dos alunos consideram importante essa participação. Contudo, no que concerne à existência de espaços de participação dos alunos na definição das regras e do funcionamento da escola, cerca de $56 \%$ responderam que esses espaços não existem, outros $41 \%$ os reconhecem em suas escolas. Ainda, mesmo havendo esses espaços, $40 \%$ dos jovens responderam que os alunos não participam. Por outro lado, 35\% dos jovens responderam que há a participação dos alunos nesses espaços.

\section{VIOLÊNCIA ESCOLAR}

O tema da violência escolar entrelaça-se com as dificuldades e as contradições existentes nas formas de se educar na contemporaneidade. Existem conflitos e transformações resultantes de modificações históricas das duas grandes instituições consagradas como responsáveis pela educação: a escola e a família.

Os conceitos de violência nas escolas passam por diferentes formulações, porém é clara a necessidade de considerar-se a multiplicidade causal desse fenômeno. Há definições que abarcam desde comportamentos indisciplinados ou maus comportamentos dos alunos, nem sempre considerados como problemas nas escolas, até as agressões físicas brutais, incluídas nas transgressões legais a serem punidas judicialmente. Ou ainda, o conceito de violência nas escolas aparece como expressão do sujeito numa dimensão psicológica, levando à sua adjetivação como violência velada, sentida, temida ou subjetiva.

Esta pesquisa arrolou uma gama de comportamentos considerados violentos numa perspectiva ampla acerca da violência. Havia a intenção de se apresentar um leque maior de possíveis situações ou atitudes, para que diferentes concepções presentes entre os jovens pudessem ser contempladas. 
Foram questionados quais os tipos de punições, contra os alunos, eram mais utilizadas nas escolas. Cerca de $32 \%$ dos alunos citaram as advertências como a punição mais utilizada. Nessa questão, era possível ao aluno descrever outros tipos de acontecimentos não relacionados como opção de escolha; foram citadas situações, tais como: ameaça, "chamam a polícia", "levam para o NAI"14", "xingo".

\begin{tabular}{rr}
\hline Tabela 2: Situações e Atitudes consideradas "Violência" \\
Situações e Atitudes & Percentual \\
agressão física & $94 \%$ \\
agressão com material ou objetos & $86 \%$ \\
racismo & $77 \%$ \\
agressão ou perseguição sexual & $76 \%$ \\
roubo & $73 \%$ \\
ameaça & $68 \%$ \\
preconceito & $67 \%$ \\
agressão verbal & $65 \%$ \\
quebrar material ou equipamentos da escola & $61 \%$ \\
usar drogas na escola & $57 \%$ \\
humilhar o outro & $56 \%$ \\
desrespeito & $56 \%$ \\
pichações & $49 \%$ \\
tomar bebida alcoólica na escola & $46 \%$ \\
autoritarismo/abuso de poder & $44 \%$ \\
fumar na escola & $43 \%$ \\
machismo & $40 \%$ \\
falta de material ou equipamentos na escola & $15 \%$ \\
falta de professor & $9 \%$ \\
outros & $2 \%$ \\
brancos & $1 \%$ \\
\hline & $34 \%$ \\
\hline
\end{tabular}

É interessante notar que sequer 'agressão física' que, aparentemente, no senso comum seria, unanimemente, considerada uma atitude violenta, não é assim compreendida pelo total dos alunos questionados, apesar do alto percentual. Menos da metade dos alunos não considera pichações, abuso de poder, machismo, assistir a uma cena de violência, usar drogas e álcool na escola como situações de violência. Na categoria 'outros' é possível identificar: matar, estupro e guerra como situações citadas pelos alunos, ainda que, a possibilidade de nomear outras violências, não contempladas nos demais itens, tenha sido raramente utilizada. 
Pretendeu-se compreender as situações de violência que acontecem na escola. Para tanto, manteve-se a gama de comportamentos possivelmente considerados violentos com aquele mesmo intuito de abarcar diversas perspectivas acerca da violência. Nessas questões, os alunos deveriam considerar as situações de violência naquela escola e, ainda, a partir do momento em que eles iniciaram o Ensino Médio.

\begin{tabular}{rc} 
Tabela 3: Situações e Atitudes "Violentas" na Escola \\
Situações e atitudes & Percentual \\
agressão verbal & $67 \%$ \\
desrespeito com os professores & $62 \%$ \\
fumar na escola & $60 \%$ \\
agressão física & $59 \%$ \\
pichações & $58 \%$ \\
desrespeito com os alunos & $56 \%$ \\
desrespeito com a direção & $56 \%$ \\
quebrar material ou equipamentos da escola & $55 \%$ \\
falta de professor & $54 \%$ \\
humilhar o outro & $51 \%$ \\
falta de material ou equipamentos na escola & $48 \%$ \\
usar drogas na escola & $48 \%$ \\
ameaça & $47 \%$ \\
roubo & $47 \%$ \\
preconceito & $44 \%$ \\
racismo & $41 \%$ \\
tomar bebida alcoólica na escola & $35 \%$ \\
agressão com material ou objetos & $29 \%$ \\
agressão ou perseguição sexual & $20 \%$ \\
brancos & $6 \%$ \\
\hline & $39 \%$ \\
autoritarismo/abuso de poder & $36 \%$ \\
\hline
\end{tabular}

Dessa maneira, em relação às situações/atitudes que os alunos afirmavam já ter acontecido na sua escola, nota-se que agressões verbais, desrespeito com os professores, fumar na escola e agressão física são as mais presentes. Em relação àquelas situações apontadas por menos da metade dos alunos como violentas, como, por exemplo, o uso de drogas, embora não sejam consideradas como atos violentos por muitos alunos, foram marcadas como presentes nas escolas.

Em relação às situações/atitudes que os alunos afirmam terem presenciado na escola, o desrespeito com professores e alunos, a agressão verbal e física e a falta de 
professor são situações indicadas por mais da metade dos alunos. A falta de equipamentos/materiais na escola e a humilhação apareceram em $41 \%$ das respostas, enquanto cerca de $30 \%$ apontaram o preconceito, o racismo e o machismo como violências presentes. O uso de drogas na escola mantém índices ainda mais altos (23\%) quando comparados ao uso de bebida alcoólica (19\%). Foram arroladas também: roubo (15\%) e agressão ou perseguição sexual (6\%).

Quando se compara quais violências já aconteceram com alunos de $1^{\circ}$ e $3^{\circ}$ anos na escola, observamos uma expressiva diferença na porcentagem referente ao desrespeito aos alunos. No $1^{\circ}$ ano, essa categoria aparece com $89 \%$ e, no $3^{\circ}$, com $17 \%$. Acredita-se que essa diferença não tenha relação somente com a exposição a esse tipo de violência, mas com a forma como os alunos a vêem. Uma interpretação possível para esse fato é a de que alunos de $3^{\circ}$ ano tenham tido essa experiência repetidas vezes, por se encontrarem há mais tempo na escola e, portanto, a tenham banalizado. Já os alunos de $1^{\circ}$ ano, não tendo sofrido tantos episódios de desrespeito no Ensino Médio, ainda se encontram sensíveis a esse tipo de violência.

$\mathrm{Na}$ comparação entre situações de violência que aconteceram com alunos de escolas centrais e periféricas, nas escolas centrais o desrespeito com alunos, o autoritarismo/abuso de poder e a falta de professor alcançaram porcentagens mais significativas do que nas escolas periféricas. Nestas, a agressão física, as pichações, o desrespeito com professores, a falta de materiais ou equipamentos na escola e o racismo tiveram valores maiores quando comparados às escolas centrais. Um fato importante nessas escolas é a presença do inspetor com formação/experiência de segurança, representando uma figura que, muitas vezes, utiliza o desrespeito e o autoritarismo em suas ações para coagir os alunos. Vê-se, neste caso, a inclusão de ações 'policialescas' nas escolas como forma de garantir a ordem, ações estas que seguem um caminho inverso ao da garantia e do respeito aos direitos desses jovens.

Os alunos foram questionados sobre quais foram os seus sentimentos mais fortes quando passaram por, ou assistiram a, situações de violência. Sentimentos como raiva/ódio e vontade de vingança, e outros similares (vontade de 'matar') receberam muitas citações, alcançando um patamar que representa mais de $70 \%$ dos sentimentos assinalados. O medo e a insegurança vêm em segundo lugar, com mais de $63 \%$ de 
citações do total, enquanto vergonha, inferioridade e solidão somam $37 \%$ de referências. Situações de violência fizeram com que $11 \%$ dos alunos tivessem vontade de abandonar a escola. Dessa forma, sentimentos relacionados ao medo, à humilhação e à incapacidade pessoal, também apresentados como "tristeza", "vontade de denunciar" e "medo que aconteça comigo", somados àqueles categorizados como insegurança, inferioridade, vergonha, solidão e vontade de abandonar a escola, alcança a maior prevalência entre os alunos. São, portanto, esses os sentimentos que a maioria dos alunos experimenta quando submetidos a situações de violência.

No que se refere às pessoas procuradas pelos alunos quando estes sofreram ou assistiram a uma cena de violência, a maioria dos alunos ou procura a família ou não procura ninguém. Em relação aos profissionais na escola, a direção é a mais requisitada.

Foram arroladas situações em que os alunos citavam fatos que ocorreram na escola relacionados ao uso de drogas, ao uso de bebida alcoólica e à presença de aluno com armas.

Quanto ao uso de drogas na escola, 44\% citam o uso de maconha; o uso de cocaína chega a $4 \%$ do total; e, por fim, a porcentagem correspondente às respostas que poderiam ser utilizadas pelos alunos, caso optassem por indicar alguma substância não descrita, neste caso, é de $12 \%$. Na categoria 'outras' apareceram: cigarros, lança perfume, crack (pedra), êxtase, LSD, cola.

O uso de bebidas alcoólicas é assim discriminado: 22\% de uso de pinga seguido de $19 \%$ de uso de cerveja e, em relação aos outros tipos enunciados pelos alunos, vinho, vodka, conhaque, além de batidas e caipirinhas, somam 9\% do total. As respostas em branco atingem $62 \%$. Assim como na questão anterior, as respostas em branco podem significar a ausência da situação, ou que não se soube ou, ainda, não se quis responder.

Outro tópico abordado referiu-se à presença de armas na escola. A presença de armas brancas na escola foi afirmada em $29 \%$ das respostas. Em relação aos instrumentos de luta, como soco inglês e outros, sua incidência foi de $13 \%$. Alunos com armas de fogo na escola somam 9\% das respostas; embora este total seja, aparentemente, pequeno, trata-se de um dado extremamente preocupante e importante, considerando-se a periculosidade da situação. A categoria 'outros' esteve presente em 
$1 \%$ das respostas na quais os alunos enunciaram armas tais como: "pau", "lança" e "bombas".

Indagou-se se os alunos consideravam a escola violenta. Embora os dados revelem uma série de situações violentas presentes na escola, a maioria dos alunos, cerca de 55\%, não considera sua escola violenta. A soma daqueles que consideram a escola violenta (seja muito ou um pouco violenta) chega a $40 \%$. Ao analisarmos os dados referentes às considerações se a escola é ou não violenta, verifica-se que muitas das atitudes/situações presentes na escola que poderiam ser classificadas como violência não são assim consideradas pelos alunos, embora eles apontem sua presença.

Uma explicação possível para isso é o fato dessas violências tornarem-se atitudes/situações rotineiras. A simbologia do que é violência passa a ser configurada por fatos cada vez mais graves ou cruéis e, ainda, as situações arroladas no instrumento utilizado podem não ser consideradas violentas, por estarem sendo banalizadas devido à proximidade e à constância com que estão presentes no cotidiano escolar.

Observa-se que os mecanismos que a escola possui para manter a disciplina, o "bom" comportamento, num primeiro momento, são as conversas, conselhos e/ou cobranças. Muitas vezes, recorre-se às famílias, mas, em muitos relatos, a família pouco pode auxiliar a escola nessas questões. Se logo depois dessas atitudes não se tem o efeito esperado, a escola utiliza métodos repressivos, desde a advertência e a suspensão até a transferência compulsória. Alguns castigos também são apontados pelos alunos: varrer o chão da escola, ficar para fora da sala de aula, levar "xingo" (da coordenação, da escola e da polícia), entre outros.

A tensão entre a manutenção da ordem e o exercício democrático do poder no Estado de Direito faz-se presente, também, na ação da organização policial. Segundo Costa (2004), o aumento das taxas de violência urbana acabaria por forçar, de algum modo, um "endurecimento" das polícias na "luta contra o crime", o que acarretaria o uso mais freqüiente da força para realizar o controle social. Todavia, a capacidade das polícias para realizar tal controle tem se demonstrado reduzida e não são, necessariamente, os limites democráticos impostos às policias as causas de sua pouca eficiência, mas sim, a forma como a questão do controle social é colocada. O acatamento da autoridade almejado pelo Estado e seus agentes diz respeito ao grau de 
legitimidade de que a autoridade política desfruta junto à sociedade. Quanto mais legítima for percebida a forma como as polícias realizam suas tarefas, mais fácil será a aceitação da sua autoridade e, portanto, menor a necessidade de recurso à violência (Costa, 2004).

A "paz social" não significa, necessariamente, justiça escolar e um estabelecimento calmo - pode ser, apenas, um instrumento de controle social e de reprodução das desigualdades (Debarbieux et al., 2003). Quando a escola recorre à polícia para o enfrentamento desses comportamentos, legitima o recurso da violência para lidar com as atitudes violentas dos alunos. Dessa forma, a questão educacional é colocada à prova, pois se substituiu o que lhe é de direito pela punição - a aprendizagem pela repressão.

\section{Conclusões}

A proposta deste estudo se deu na direção de traçarmos um perfil sócioeconômico dos adolescentes e jovens que cursam o Ensino Médio em escolas públicas de São Carlos (SP), assim como de entender qual a avaliação que estes fazem acerca da escola e do fenômeno da violência $n a$ e $d a$ escola, tomando o caso como típico para muitas cidades brasileiras.

Dentre os principais motivos que fizeram os alunos deixarem de freqüentar a escola ou pensarem em abandoná-la estão a falta de interesse, vontade e motivação, o cansaço e o desânimo, a falta de vagas e o trabalho. É importante nos questionarmos sobre o que a escola tem oferecido a seus alunos para que eles permaneçam na escola? Basta a 'entrada' de todos na escola para se configurar o 'acesso' à educação e para se consolidar a educação democrática?

A escola deve ser um equipamento social democrático e com bases participativas, onde ocorra o efetivo aprendizado do exercício da cidadania, com seus direitos e deveres derivados. Ela é o espaço público de maior abrangência para crianças, adolescentes e jovens de grupos populares urbanos e, por isso, um equipamento importante na construção da cidadania e de referenciais democráticos. 
A incorporação de noções e atitudes democráticas requer, necessariamente, experiências democráticas. Ensinar democracia não passa pela aquisição da informação; é muito mais que um conceito: é uma conduta ética. Neste sentido, a maior dificuldade está na falta de experiências democráticas que construam caminhos de inserção e de garantia de direitos.

Sem oportunizar essas experiências, a escola cria rupturas que desencadeiam uma série de problemáticas, como a da violência escolar. Observa-se uma contradição presente nas escolas, pois, muitas vezes, sem saberem como lidar com a violência escolar, as ações coercitivas são fortalecidas em detrimento das ações educacionais no enfrentamento de situações do cotidiano escolar. As condutas adotadas são, inúmeras vezes, tanto quanto ou mais violentas que os comportamentos inadequados originais.

Nesse contexto, os alunos assinalaram várias situações de violência que aconteceram na escola e que aconteceram com eles próprios. Apesar de mais da metade dos jovens não considerar sua escola violenta, o mesmo percentual refere a ocorrência de situações de desrespeito, de humilhação, de agressão verbal e física, de uso de drogas na escola. Isto porque tais violências têm se integrado ao cotidiano escolar e têm sido banalizadas.

Nossa pretensão é que esse perfil possa oferecer referências para estratégias de enfrentamento da violência na e $d a$ escola, associadas à promoção dos direitos e ao contato relacional com base no respeito mútuo (Sennett, 2004), sem a necessidade dos adolescentes e dos jovens sentirem-se subjugados ou submetidos em situações como as quais convivem em seu cotidiano.

Os dados aqui trazidos, somados à nossa experiência em projetos de extensão universitária, nos expõem refinadas estratégias do processo de inclusão e exclusão sociais reproduzidas pela escola, assim como, a dinâmica dos agentes escolares em relação aos processos de violência, suas reproduções e seus enfrentamentos. A escola sofre com as ameaças internas e externas que estão presentes no seu cotidiano e enfrenta a árdua tarefa de conciliar métodos repressivos/punitivos e construção de práticas democráticas. Ressaltamos que não se considera a educação, ou a escola, como a solução dos problemas sociais, contudo, busca-se que cumpra seu papel, no quadro mais geral de um desenvolvimento sustentado e de longo prazo para o país. 
Tais questões demandam intervenções, pois, com o apelo eficaz do medo com o qual a sociedade contemporânea convive, produz e recria, assistimos à distorção dos anseios na luta pelas liberdades democráticas; em nome da segurança, novos muros se erguem, se renovam padrões de censura e de cerceamento.

Esses adolescentes e jovens têm vivido um processo de invisibilidade que os coloca à margem das ações públicas, da participação e do acesso a bens sociais. Ganham um lugar social "somente" quando assumem o papel de autores de violência. Daí a necessidade de discussão do acesso dessa população aos espaços públicos e sua possibilidade de participação. Os espaços públicos, conforme Hannah Arendt (1995), pautam-se pela dimensão do reconhecimento do direito, do bem público, publicizando conflitos, criando arenas para seu encaminhamento.

É necessário avançar para a construção de espaços que garantam a voz e a escuta do jovem, por meio de sua participação direta, de maneira a efetivar o diálogo, criandose, assim, subsídios para políticas públicas cujo impacto se dê na direção de promover a diminuição da desigualdade, da discriminação e da violência a que está sujeita a maioria dos adolescentes e jovens no Brasil.

\section{Referências Bibliográficas}

ABRAMOVAY, Miriam; RUA, Maria das Graças. Violência nas escolas. Brasília: UNESCO, 2002, 400p.

ARENDT, Hannah. A condição humana. $7^{\text {a }}$. ed. Rio de Janeiro: Forense Universitária, $1995,352 \mathrm{p}$.

ARIÈS, Philippe. História social da criança e da família. $2^{\mathrm{a}}$.ed. Rio de Janeiro: Zahar, 1981, 279p.

BRASIL. Ministério da Educação, INEP. Disponível em http://www.inep.gov.br/. Acesso em: setembro de 2006.

BRASIL. Lei № 9.394. Estabelece as Diretrizes e Bases da Educação Nacional. Diário Oficial da União. Brasília, 1996.

BRASIL. Estatuto da Criança e do Adolescente. São Paulo : Cortez, 1990. 
CASTEL, Robert. As metamorfoses da questão social: uma crônica do salário. Petrópolis: Vozes, 1998, 611p.

COSTA, Arhur. Entre a lei e a ordem: violência e reforma nas polícias do Rio de Janeiro e Nova York. Rio de Janeiro : FGV, 2004, 203p.

DEBARBIEUX, Éric; BLAYA, Catherine. (Org.) Violência nas escolas: dez abordagens européias. Brasília: UNESCO, 2002, 268p.

DEBARBIEUX, Éric et al. Desafios e alternativas: violências nas escolas. Brasília: UNESCO/UNDP, 2003, 280p.

DUBET, François. A escola e a exclusão. Cadernos de Pesquisa, 2003, n. 119, p.29-45.

FOLHA DE S. PAULO. 27\% dos jovens não trabalham nem estudam. São Paulo, 20 fev. 2006, Cotidiano, p. C1.

GONÇALVES, Lia; PASSOS, Sara; PASSOS, Álvaro. Novos rumos para o Ensino Médio noturno - como e por que fazer? Ensaio: Avaliação e Políticas Públicas em Educação. Rio de Janeiro, v.13, n.48, p. 345-360. jul./set. 2005.

INSTITUTO BRASILEIRO DE GEOGRAFIA E ESTATÍSTICA. Pesquisa Nacional por Amostra de Domicílios. Rio de Janeiro, 2001/2002. Disponível em www.ibge.gov.br. Acesso em: fevereiro de 2007.

MARCÍlLIO, Maria Luiza. História da escola em São Paulo e no Brasil. São Paulo: Instituto Fernand Braudel e Imprensa Oficial do Estado de São Paulo, 2005, 485p.

MINAYO, Maria Cecília; RAMOS, Edinilsa. (Org.). Violência sob o olhar da saúde: a infrapolítica da contemporaneidade brasileira. Rio de Janeiro: Editora Fiocruz, 2003, $284 \mathrm{p}$.

LOPES, Roseli. et al. Juventude pobre, violência e cidadania. Saúde e Sociedade, v. 17, p. 63-76, 2008.

LOPES, Roseli; SILVA, Carla; MALFITANO, Ana Paula. Adolescência e juventude de grupos populares urbanos no Brasil e as políticas públicas: apontamentos históricos. Revista HISTEDBR On-line, v. 23, p. 114-130, 2006.

ORGANIZACIÓN MUNDIAL DE LA SALUD (OMS); ORGANIZACIÓN PANAMERICANA DE LA SALUD (OPS). La salud del adolescente y el joven em las Américas. Washington, DC, 1985.

ORGANIZAÇÃO DAS NAÇÕES UNIDAS (ONU). World youth report 2005: young people today, and in 2015. United Nations Publication. October, 2005.

SANTOS, José. A violência na escola: conflitualidade e ações civilizatórias. Educação e Pesquisa. São Paulo, v.27, n.1, p.105-122. jan/jun, 2001.

SPOSITO, Marília. Um breve balanço da pesquisa sobre a violência escolar no Brasil, 
Educação e Pesquisa, v.27, n.1, p.87-103, jan/jun. 2001.

SENNETT, Richard. Respeito: a formação de um caráter em um mundo desigual. Rio de Janeiro: Record, 2004, 333p.

WAISELFISZ, Julio. Relatório de desenvolvimento juvenil. Brasília, DF: Rede de Informação Tecnológica Latino-Americana (RITLA), 2007, 167.

ZIBAS, Dagmar. Refundar o Ensino Médio? Alguns antecedentes e atuais desdobramentos das políticas dos anos de 1990. Educação e Sociedade. Campinas, v. 26, n. 92, p. 1067-1086. out. 2005.

Notas:

\footnotetext{
${ }^{1}$ Este trabalho contou com o apoio do Conselho Nacional de Desenvolvimento Científico e Tecnológico CNPq, da Fundação de Amparo à Pesquisa do Estado de São Paulo - FAPESP e da Secretaria de Ensino Superior do Ministério da Educação, através do Programa de Apoio à Extensão Universitária Voltado às Políticas Públicas - PROEXT 2005/2006.
}

Parte dos dados da pesquisa que compõe este texto foi apresentada na VIII Jornada do HISTEDBR História, Sociedade e Educação no Brasil, realizada em São Carlos (SP), em julho de 2008.

Todos os procedimentos da pesquisa que integra este artigo estiveram submetidos aos preceitos éticos necessários à sua realização.

${ }^{2}$ Professora Associada do Departamento de Terapia Ocupacional e do Programa de Pós-Graduação em Educação da Universidade Federal de São Carlos (UFSCar). Integrante do Núcleo UFSCar do HISTEDBR. Coordenadora do Grupo de Pesquisa Terapia Ocupacional e Educação no Campo Social CNPq. Pesquisadora CNPq.

${ }^{3}$ Mestre e Doutoranda em Educação pela UFSCar. Integrante do Grupo de Pesquisa Terapia Ocupacional e Educação no Campo Social. Bolsista FAPESP.

4 Terapeuta Ocupacional pela UFSCar. Integrante do Grupo de Pesquisa Terapia Ocupacional $e$ Educação no Campo Social. Bolsista de IC/CNPq.

${ }^{5}$ Professor Associado do Departamento de Estatística da UFSCar.

${ }^{6}$ Define-se como em situação de pobreza aqueles jovens que vivem com menos de U\$1,0 (um dólar) por dia; se considerados os jovens que vivem com menos de U\$2,0 por dia, passa-se a 515 milhões, ou seja, $45 \%$ do total dessa população no mundo (ONU, 2005).

${ }^{7}$ Divididas nas etapas de pré-adolescência (dos 10 aos 14 anos) e de adolescência propriamente dita (de 15 a 19 anos).

${ }^{8}$ Em relação aos jovens, sobretudo aqueles de grupos populares, a violência tem se tornado constante e banalizada. Inúmeros dados têm demonstrado que esses jovens se encontram em situação de maior vulnerabilidade à violência, sendo esta considerada um grave problema para a saúde pública no Brasil e constituindo-se na principal causa de morte de adolescentes (Minayo e Ramos, 2003; Waiselfisz, 2007).

${ }^{9}$ Localizada na área central do estado de São Paulo, distante cerca de $230 \mathrm{~km}$ de sua capital, tem 220.425 habitantes, um IDH (Índice de Desenvolvimento Humano) de 0,841 e um PIB (Produto Interno Bruto) de 
R\$ 2.472.749.700,00, o que implica em um PIB per capita de R\$ 11.950,62. Fonte: Prefeitura de São Carlos, http://www.saocarlos.sp.gov.br/ - Acesso em outubro de 2008.

${ }^{10}$ São Carlos não possui escolas de Ensino Médio da rede municipal.

${ }^{11}$ Termo utilizado pelos jovens.

${ }^{12}$ Os dados referentes aos alunos que estudam em escolas centrais dizem respeito a 658 jovens, os alunos que estudam em escolas periféricas representam outros 521 jovens. Das cinco escolas que participaram da pesquisa, duas se enquadraram na classificação escola central e outras duas na classificação escola periférica.

13 O período noturno foi composto por 425 jovens (30\%) e o diurno por 1020 jovens (70\%).

14 O Núcleo de Atendimento Integrado - NAI - de São Carlos é o órgão público responsável pelos cumprimento dos artigos 171 a 190 do ECA (Brasil, 1990), quanto à apuração de ato infracional de adolescentes. 